\title{
United Kingdom-East and Southern Africa Partnership at the Forefront of Developing the First Ever Test that Measures Patient Tuberculosis Burden in Hours
}

\author{
Wilber Sabiitia on behalf of the MBLA development stakeholders ${ }^{b}$ \\ aSchool of Medicine, University of St Andrews, Fife, UK \\ Correspondence to Wilber Sabiiti (ws31@st-andrews.ac.uk)
}

\begin{abstract}
Mycobacterium tuberculosis has caused tuberculosis (TB) in humans for at least 3 millennia, but the disease has evaded eradication efforts by all human civilisations despite promising technological advancements. The World Health Organization (WHO) has set a target of ending the TB epidemic by 2035. Going by the current rate of progress, it is estimated that it will take another 160 years to realise the WHO End TB Strategy's target. Accelerating the eradication of TB will require effective tools for diagnosis, vaccines and medicines to treat the disease, and efficient implementation thereof. This presents a great opportunity for innovators in East Africa and the world over to chip in and develop the best technologies to end TB. With funding from the European and Developing Countries Clinical Trials Partnership (EDCTP), partnerships between the UK-based University of St Andrews and research institutions in East and Southern Africa have led to the development of the first ever test - the molecular bacterial load assay (MBLA) - that measures the number of TB bacteria in a patient and reveals if this number is declining as a patient progresses on treatment. Initial assay results are available within 4 hours. Real-time knowledge of patient mycobacterial burden and the effectiveness of prescribed medications are crucial for timely clinical decisions on patient management.
\end{abstract}

\section{INTRODUCTION}

1 ycobacterium tuberculosis has caused tuberculosis ease has evaded eradication efforts by all human civilisations despite promising technological advancements. The disease is transmitted via the inhalation of aerosols laden with TB bacilli, expelled when infected individuals cough. One-third of the world's population is latently infected with TB, reflecting one of the largest reservoirs of disease through asymptomatic carriers, from which an unfortunate $5 \%$ of cases progress to active disease. ${ }^{1}$ Close to 10 million new cases and over 1 million TB-related deaths were reported in $2017 .^{2}$ Although TB is a global disease, the burden varies greatly between highand low-income countries. Asia and Africa, which host the most low- and middle-income countries (LMICs), account for the highest burden of $\mathrm{TB} .^{2}$ According to the World Health Organization (WHO), 30 countries are categorised as high-TB-burden countries (HBCs) and account for $87 \%$ of the global TB burden. Seventeen (56\%) of the HBCs are in Africa, of which 8 (47\%) are in eastern and southern Africa. ${ }^{3}$ Countries from the eastern-south- ern African HBC block (ES) ${ }^{4}$ are recognised as having the highest burden of multidrug-resistant TB. ${ }^{1-3}$ The need for these countries to invest in developing effective tools to solve the TB problem cannot be overemphasised.

The WHO has set a target of ending the TB epidemic by $2035 .{ }^{4}$ Going by the current rate of progress, it is estimated that it will take another 160 years to realise the WHO End TB Strategy's target. ${ }^{5}$ Accelerating the eradication of TB will require effective tools for diagnosis, vaccine and medicines to treat the disease, and efficient implementation thereof. This presents a great opportunity for innovators in ES and the world over to chip in and develop the best technologies to end TB. With funding from the European and Developing Countries Clinical Trials Partnership (EDCTP), partnerships between the UK-based University of St Andrews and research institutions in ES have led to the development of the first ever test - the molecular bacterial load assay (MBLA) - that measures the number of TB bacteria in a patient and reveals if this number is declining as a patient progresses on treatment. ${ }^{6,7}$ Assay results are available at the laboratory within 4 hours of sample receipt. Real-time knowl- 
edge of patient mycobacterial burden and the effectiveness of prescribed medications are crucial for timely clinical decisions on patient management.

This is a great improvement over the tools currently used for TB diagnosis and treatment monitoring. The gold standard test - M. tuberculosis culture - takes weeks or months to deliver results, which is too slow to inform patient management. Furthermore, culture is acutely sensitive to endogenous and exogenous contaminants, such as non-TB bacteria and fungi, which grow rapidly and cause false-positive time to culture positivity (TTP) results. ${ }^{8,9}$ Consequently, a result from culture requires 3 extra confirmatory tests: (1) acid-fast microscopy to confirm acid-fast bacilli, (2) blood agar culture to rule out contamination, and (3) an antigen test, MPT64, to confirm the presence of $M$. tuberculosis. These extra tests consume more person-hours and increase the total cost associated with culturing. Smear microscopy, which is widely available and less expensive, is less sensitive and cannot distinguish between live and dead bacteria. ${ }^{10}$ This limits the utility of smear microscopy when it comes to low-burden TB patients, such as children and people living with HIV, and makes it a poor tool for monitoring treatment responses. MBLA, therefore, is a technological solution to these challenges drawing on recent advances in molecular biology.

\section{THE MBLA TEST}

The MBLA test is specific to TB, and it has a faster turnaround time (TAT) than culture, taking only 24 hours for results to be received at the clinic. It is a reverse transcriptase quantitative polymerase chain reaction (RT-qPCR) assay that uses 16S-rRNA as a marker to detect and quantify the load of viable $M$. tuberculosis bacteria in a patient's sputum sample. The process starts with RNA isolation from $M$. tuberculosis bacteria, followed by RT-qPCR to quantify the RNA, then conversion of the RT-qPCR output (cycle threshold [CT] values) into bacterial load values (estimated colony forming units per millilitre [eCFU/ml]) using a standard curve (Figure 1).

Unlike DNA, which can persist long after cells have died, RNA degrades following cell death, implying that the RNA measured by MBLA is from viable cells. The principle is that for patients responding to treatment, the number of viable $M$. tuberculosis bacilli remaining following treatment should be fewer than before treatment, and this number should continue declining until there is zero (undetectable) mycobacterial load. Changes in mycobacterial load can be detected as early as the third day of treatment follow-up. This means that drug resistance or nonadherence to treatment can be detected earlier and appropriate measures can be taken. The EDCTP-funded Pan-African Biomarker Expansion (PANBIOME) study - conducted in Malawi, Mozambique, and Tanzania - demonstrated that patients, on average, clear $1 \log _{10} \mathrm{eCFU} / \mathrm{ml}$ of $M$. tuberculosis bacteria per week of treatment (Figure 2).

\section{TAKING THE MBLA INTO POLICY AND PRACTICE}

Many tools are invented but are never implemented in practice or are too expensive to be accessed by the majority. The other challenge with new technologies is their frequent incompatibility with existing infrastructure or environmental conditions in the target areas of implementation. Taking MBLA to policy and practice refers to all processes - including technical optimisation and validation, assessment of appropriateness, acceptability and cost-effectiveness - that are required for the tool to be adopted for the routine clinical management of TB. After a stakeholders conference, the WHO identified MBLA as having the potential to replace smear microscopy and culture for monitoring TB treatment responses. ${ }^{2}$ Importantly, the development of MBLA has taken a co-development model with stakeholders to ensure that the capacities needed to sustain the test at sites of implementation are developed in advance.

The first trial that demonstrated MBLA as a culture-free biomarker test for rapidly measuring patient mycobacterial load was conducted at South Africa's Stellenbosch University. This study also demonstrated that the reduction in mycobacterial load measured by MBLA was consistent with the increase in TTP measured by automated TB liquid culture, Mycobacterium Growth Indicator Tube (MGIT). ${ }^{11}$ The difference between the 2 technologies is that MBLA is quantitative, contamination-free, and produces results within hours, compared with 5 to 42 days for MGIT. A second study, conducted at Tanzania's National Institute for Medical Research (NIMR)-Mbeya Medical Research Centre, revealed superior performance of MBLA over solid TB culture in quantifying mycobacterial load and the assay results TAT. ${ }^{12}$ Funded by the EDCTP, the first multi-site evaluation of the test was conducted at the University of Malawi College of Medicine, Instituto Nacional de Saude, Kilimanjaro Clinical Research Institute, and NIMR-Mbeya Medical Research Centre in Malawi, Mozambique, and Tanzania, respectively. ${ }^{6}$ The study revealed that MBLA results are reproducible in different laboratory settings and that it is superior to existing tools for the long-term follow-up of TB patients and monitoring treatment response (Figure 2). Unlike culture, wherein reported contamination rates were as high as $30 \%$ in some settings, MBLA was found to be unsusceptible to contamination and inhibition. ${ }^{13}$ Further trials are ongoing in Uganda, Tanzania, Vietnam, Thailand, and the UK. The Pan African Consortium for the Evaluation of Antituberculosis Antibiotics (PanACEA) has adopted MBLA as a primary test in their clinical trials at over 10 sites in East and Southern Africa, as well as Gabon in Central Africa.

With support from the Global Challenges Research Fund (GCRF) and the Scottish Funding Council (SCF), the first-ever MBLA stakeholders conference was held at the University of St Andrews from 11 to 13 June 2018. Directors of national TB control programmes, laboratory scientists, academics, and industrialists representing 16 countries and WHO participated 


\section{FIGURE 1. Diagrammatic Representation of the Molecular Bacterial Load Assay (MBLA) Process}

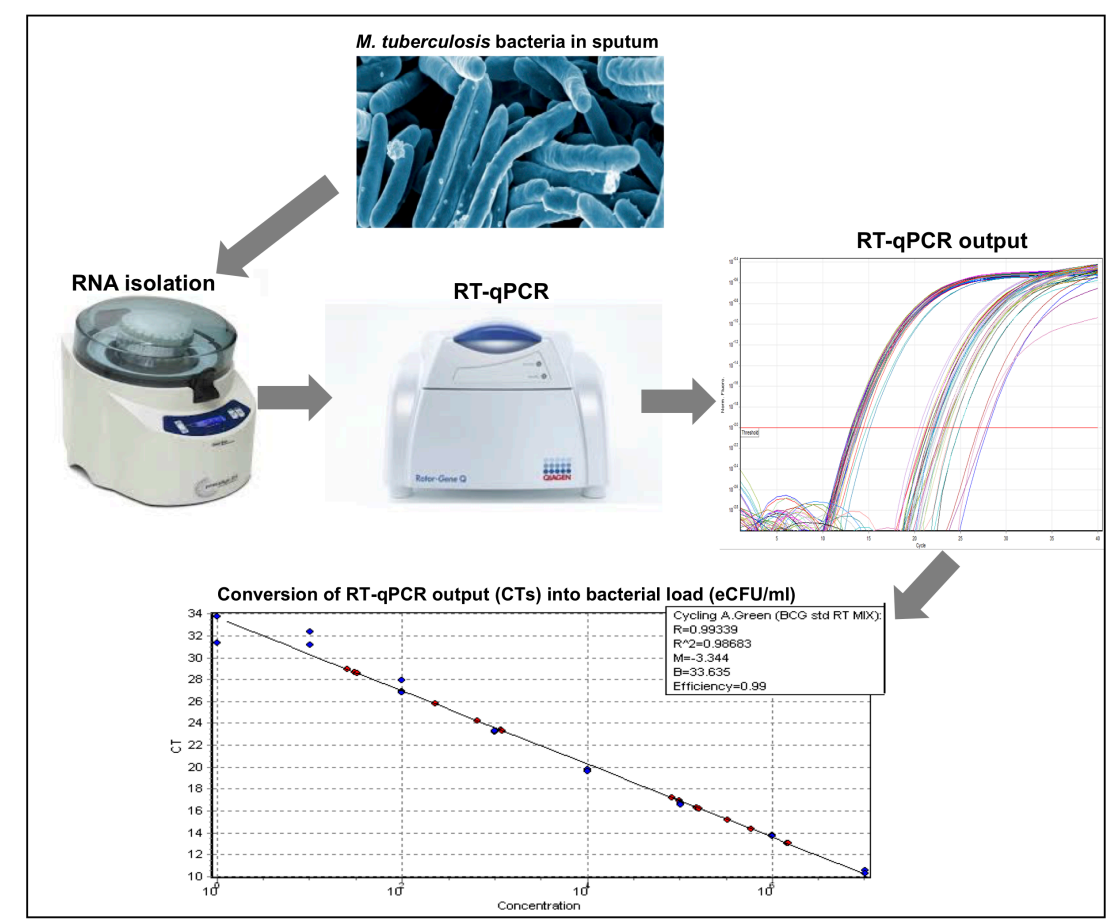

The MBLA process begins with RNA extraction from patient sputum, followed by a reverse transcriptase quantitative polymerase chain reaction (RT-qPCR) assay, and finally conversion (using qPCR analysis software [Qiagen, UK]) of the PCR output (cycle threshold [CT] values) into bacterial load values (estimated colony forming units per millilitre $[\mathrm{eCFU} / \mathrm{ml}]$ ) using a standard curve.

in the conference (Figure 3). Seventeen delegates participated in the 2-day MBLA training session, among whom $41 \%$ were from East and Southern Africa (Figure 4). WHO was represented by the Laboratories, Diagnostics, and Drug Resistance Unit of the Global TB Programme. The conference discussed ways by which the MBLA test can be translated into routine clinical practice and accessed by the TB patients who need it the most. The conference underscored what the development of TB diagnostics should focus on - tests that identify true TB infections, monitoring the effectiveness of treatment, and determining cure. In addition to the current evidence, the conference unanimously recommended a large-scale, multisite, multinational, near-routine-practice evaluation of MBLA to conclusively answer technical and operational questions required by WHO to approve the test for routine practice. This work will answer questions about MBLA test sensitivity and specificity, sample type and frequency of testing, reproducibility, appropriateness, acceptability, and cost-effectiveness in relation to the current standard of care tests for TB diagnosis and treatment monitoring.
While commonly applied in viral disease management, the molecular measurement of pathogen load (the number of microbes causing the disease) is new in bacteriology. As with other bacteria, the measurement of TB bacterial load has depended on the laboratory cultivation of sputum (and other patient samples) in culture media to count $M$. tuberculosis colonies or determine TTP as an index of mycobacterial load. Unfortunately, M. tuberculosis takes weeks to grow, and this is too long for results to inform initial patient management decisions. ${ }^{8}$ Discovered 136 years ago, and despite its shortcomings of low sensitivity and inability to distinguish between dead and viable bacteria, semiquantitative smear microscopy remains the most widely used test for TB diagnosis and treatment monitoring. ${ }^{10}$ Microscopy is often unreliable for samples from children and HIV-positive patients who often have a low TB bacterial load. Additionally, because of its low sensitivity, smear microscopy is often negative a few weeks into treatment when patients still have a significant mycobacterial load. ${ }^{14}$ 
FIGURE 2. Treatment Response Curves of Tuberculosis Patients Followed for 12 Weeks of Treatment

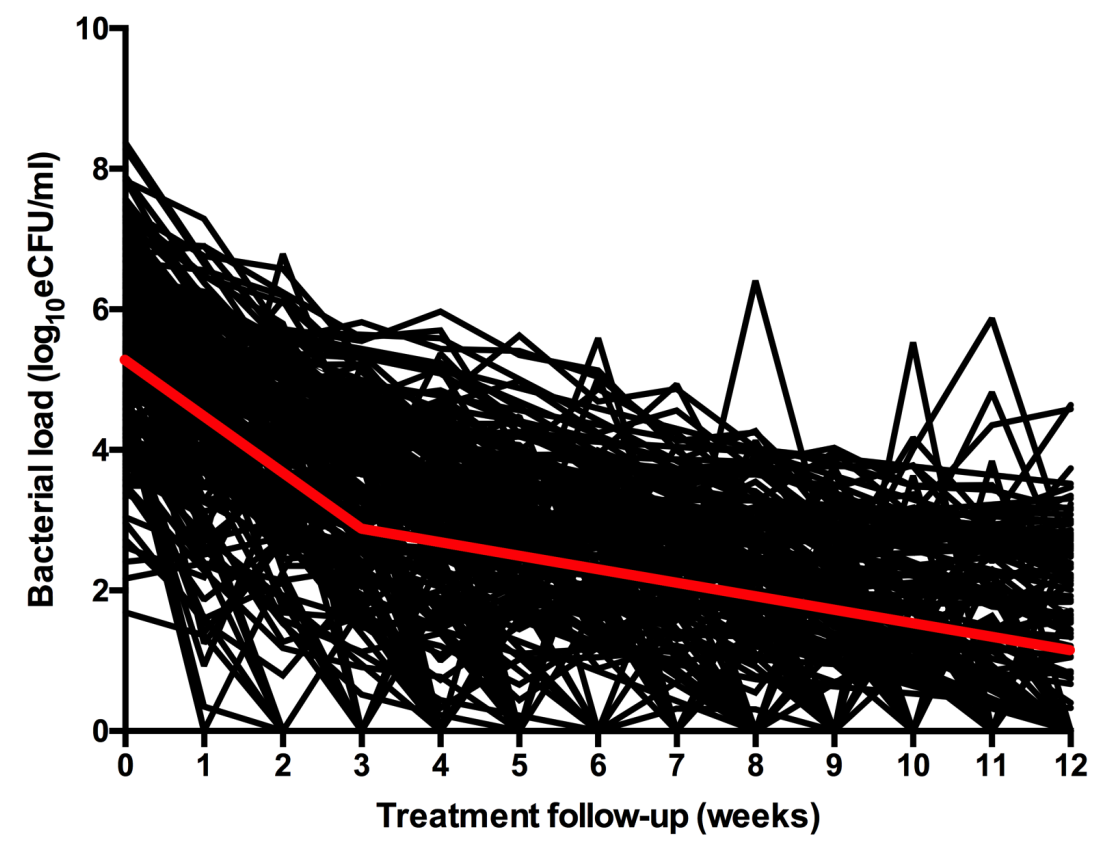

Mycobacterial load was measured at baseline before the initiation of antituberculosis therapy and weekly during treatment. Each curve represents a patient. The red curve demonstrates the biphasic decline in mycobacterial load as patients responded to treatment. Note the steeper slope (fast rate of sputum clearance) in the first 2 weeks of treatment, and then a plateauing curve (slow rate of sputum clearance) in the later weeks of treatment.

FIGURE 3. The Molecular Bacterial Load Assay (MBLA) Stakeholders Conference Delegates

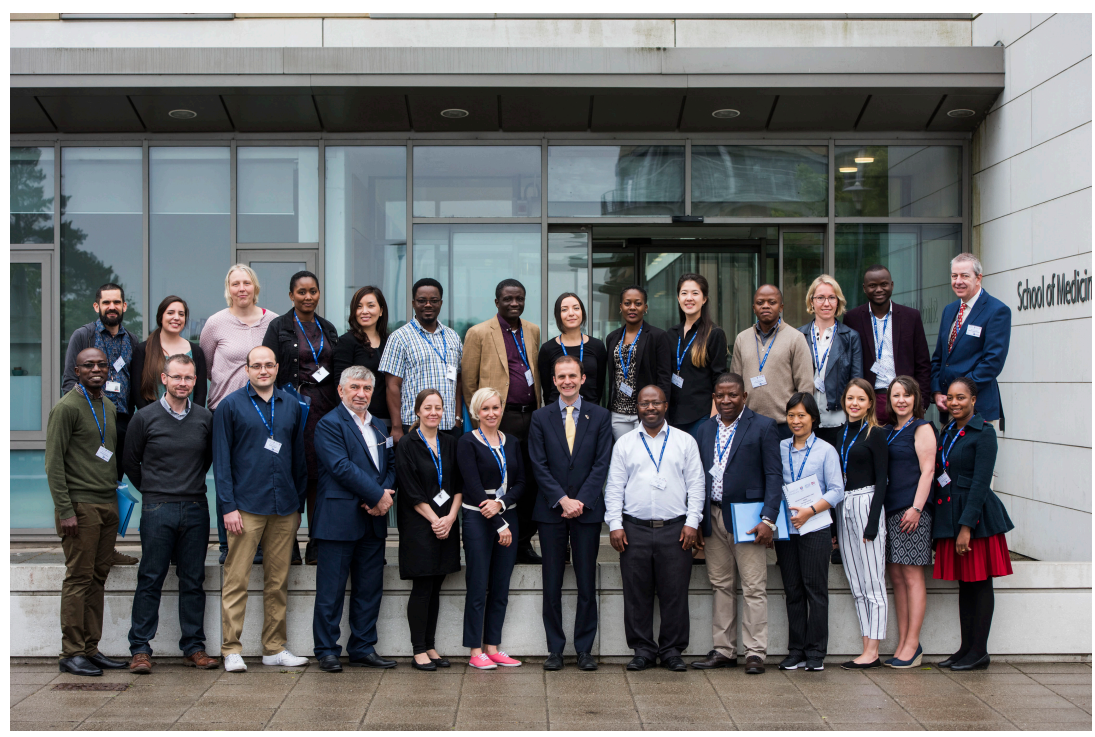


FIGURE 4. Molecular Bacterial Load Assay (MBLA) Stakeholders Conference Delegates Participating in an MBLA Training Session

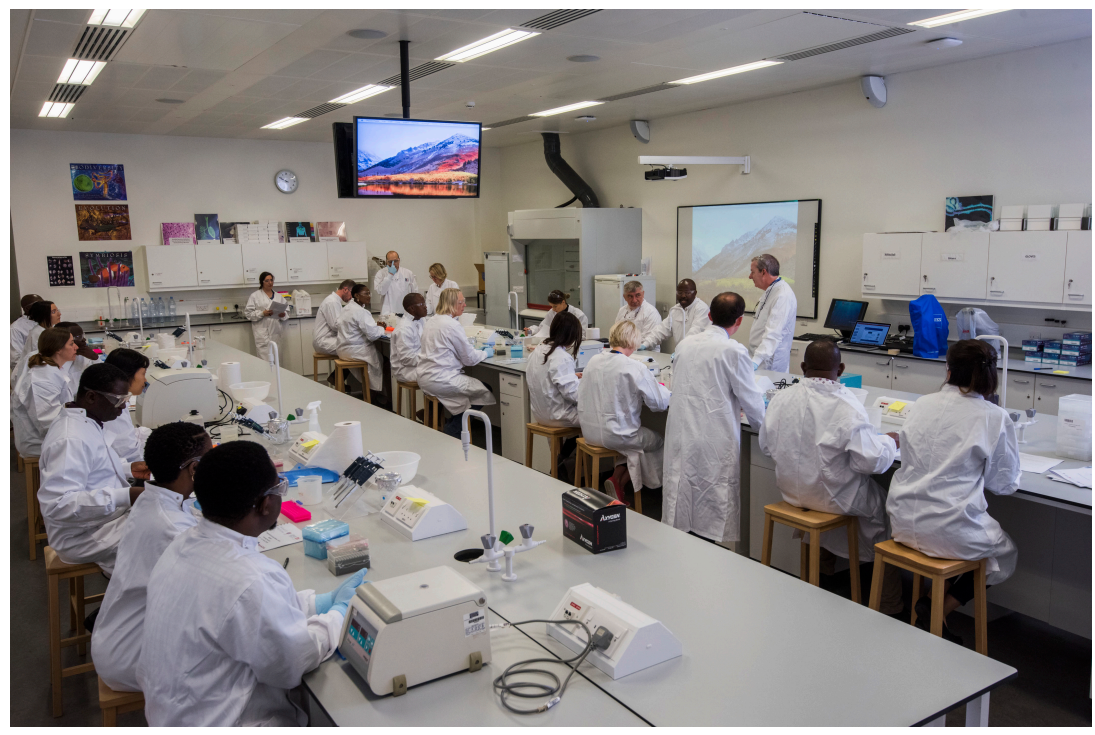

\section{THE TB CONTROL COMMUNITY SHOULD ACCELERATE IMPLEMENTATION}

Like slow-growing $M$. tuberculosis colonies, the uptake of TB diagnostic and therapeutic innovation has been disappointingly slow. After the discovery of $M$. tuberculosis bacilli using a rudimentary microscope in 1880, it took 127 years to adopt the use of light-emitting diode (LED) technologies for microscopy and for the first molecular diagnostic tool - the line probe assay - to be adopted..$^{15}$ The Xpert MTB/RIF, a rapid test that provides TB diagnostic results within 2 hours, was adopted in the 128th year. In contrast, within 10 years of describing HIV disease, viral load measurement for monitoring the response to antiretroviral therapy was adopted in clinical practice. ${ }^{16}$ After 136 years, the microscope remains the only WHO-approved tool for the routine monitoring of TB treatment, and there is still no effective rapid test to measure mycobacterial load and monitor treatment responses in routine practice. The MBLA has been developed to fill this gap and ensure the early identification and appropriate management of patients responding poorly to treatment. With MBLA, clinicians can undertake early investigations of adherence and drug resistance when the patient's bacterial load does not decline following the initiation of therapy.

\section{CONCLUSION}

Through partnerships with local and international technology developers, East Africa will leverage its capacity for biomedical innovation. In some respects, there is no need to reinvent the wheel when it comes to technologies that are already available. Frugal innovation, using existing knowledge and technology is the way to go; this way, existing technologies can be customised and repackaged for similar functions or repurposed to serve different functions of interest at affordable costs. It is important to note, however, that innovation and entrepreneurship do not happen in a vacuum. Without a conducive environment and financial resources, innovative ideas can only go so far. Governments in East Africa and Africa at large should take it upon themselves to create business incubation centres to nurture ideas from young entrepreneurs and policy frameworks to protect intellectual property rights, assuring innovators and their funders of good returns on their investments.

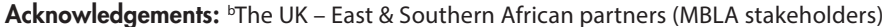
Prof. Stephen Gillespie - University of St Andrews, UK; Prof. Gibson Sammy Kibiki - East Africa Health Research Commission, Burundi; Dr Nyanda Elias Ntinginya - NIMR-Mbeya Medical Research Centre, Tanzania; Prof. Blandina Mmbaga Kilimanjaro Clinical Research Institute, Tanzania; Dr Chisomo Msefula - College of Medicine University of Malawi, Malawi; Dr Katarina Orascova - Glasgow University, UK; Dr Derek Sloan - University of St Andrews, UK; Prof. Moses Joloba Makerere University, Uganda; Dr Christine Sekaggya - Infectious Diseases Institute, Uganda; Dr Emmanuel Nasinghe - Makerere University, Uganda; Dr Nilesh Bhatt

- Institito Nacional de Saude, Mozambique; Dr Stella Mpagama - Kibong'oto Infectious Diseases Hospital, Tanzania; Prof. Gerhard Walzl - Stellenbosch University, South Africa; Dr Caroline Beltran - Stellenbosch University, South Africa; Dr Paul Smith - Lifearc, Edinburgh, UK; Mr Bariki Mtafya - NIMR-Mbeya Medical Research Centre, Tanzania; Mr Davis Kuchaka - Kilimanjaro Clinical Research Institute, Tanzania; Mr Khalide Azam - Institito Nacional de Saude, Mozambique; Ms Mercy Kamdolozi - College of Medicine University of Malawi, Malawi; Dr Isobella Honeyborne - University College London, UK; Prof. Timothy D McHugh University College London, UK

We acknowledge the European and Developing Countries Clinical Trials Partnership (EDCTP) for funding the development and trialling of the molecular bacterial load assay (MBLA) test. Funding from the Scottish Funding Council-Global Challenges 
Research Fund, the Pan-African Consortium for the Evaluation of Antituberculosis Antibiotics (PanACEA), and University of St Andrews School of Medicine made the MBLA stakeholders conference possible. Thanks to the conference organising team, trainers, the School of Biology teaching laboratory team, the School of Medicine research support office, and the delegates who made the conference a success. We also acknowledge the research institutions in East and Southern Africa who have significantly contributed to the development of the MBLA test.

\section{REFERENCES}

1. World Health Organization (WHO). Global Tuberculosis Report 2015, 20th ed. Geneva: WHO; 2015. http://www.who.int/iris/handle/10665/191102. Accessed 27 February 2019

2. World Health Organization (WHO). Global Tuberculosis Report 2018. Geneva: WHO; 2018. http://apps. who.int/iris/handle/10665/274453/. Accessed 27 February 2019.

3. Floyd K, Falzon D, Getahun H, et al. Use of High Burden Country Lists for TB by WHO in the Post-2015 Era. Geneva: World Health Organization; 2015. https://www.who.int/tb/publications/global_report/high_tb_burdencountrylists2016-2020.pdf. Accessed 27 February 2019

4. World Health Organization (WHO). Global Tuberculosis Report 2016. Geneva: WHO; 2016. http://apps.who.int/medicinedocs/en/d/Js23098en/. Accessed 27 February 2019

5. UK Parliament. Tuberculosis. House of Commons Hansard Website. Volume 642, 7th June 2018. https://hansard.parliament.uk/commons/2018-06-07/ debates/9BF50C2B-C9AF-47C5-9000-F306378A3821/Tuberculosis. Accessed 27 February 2019

6. Sabiiti W, Ntinginya N, Kuchaka D, et al. Molecular bacterial load assay: a fast and accurate means for monitoring tuberculosis treatment response [abstract OA-007]. In: Abstracts of the Eighth EDCTP Forum, 6-9 November 2016; abstracts of oral presentations. BMJ Glob Health. 2017;2(suppl 2):A8. CrossRef. Medline

7. Gillespie SH, Sabiiti W, Oravcova K. Mycobacterial load assay. In: Bishop-Lilly KA, ed. Diagnostic Bacteriology: Methods and Protocols. New York, NY: Springer New York; 2017. p. 89-105. CrossRef. Medline

8. Sabiiti W, Mtafya B, Kuchaka D, et al. Optimising molecular diagnostic capacity for effective control of tuberculosis in high-burden settings. Int I Tuberc Lung Dis. 2016;20(8):1004-1009. CrossRef. Medline
9. Azam K, Cadir N, Madeira C, Gillespie SH, Sabiiit W. OMNlgene.SPUTUM suppresses contaminants while maintaining Mycobacterium tuberculosis viability and obviates cold-chain transport. ERJ Open Res. 2018;4(1):00074-2017. CrossRef. Medline

10. Desikan P. Sputum smear microscopy in tuberculosis: is it still relevant? Indian J Med Res. 2013;137(3):442-444. Medline

11. Honeyborne I, McHugh TD, Phillips PPJ, et al. Molecular bacterial load assay, a culture-free biomarker for rapid and accurate quantification of sputum Mycobacterium tuberculosis bacillary load during treatment. J Clin Microbiol. 2011;49(11):3905-3911. CrossRef. Medline

12. Honeyborne I, Mtafya B, Phillips PPJ, et al. The molecular bacterial load assay replaces solid culture for measuring early bactericidal response to antituberculosis treatment. J Clin Microbiol. 2014;52(8):3064-3067. CrossRef. Medline

13. Sabiiti W, Azam K, Kuchaka D, et al. Improving diagnosis and monitoring of treatment response in pulmonary tuberculosis using the molecular bacterial load assay (MBLA). bioRxiv. 2019;555995v1. CrossRef

14. Ngabonziza JCS, Ssengooba W, Mutua F, et al. Diagnostic performance of smear microscopy and incremental yield of Xpert in detection of pulmonary tuberculosis in Rwanda. BMC Infect Dis. 2016;16:600. CrossRef. Medline

15. United States Agency for International Development (USAID). Path to TB innovation. USAID Website. Washington, DC: USAID; 2014. https://www.usaid. gov/sites/default/files/documents/1864/tbtimeline.pdf. Accessed 27 February 2019.

16. Avert. History of HIV and AIDS overview. Avert Website. Brighton, UK: Avert; 2015. https://www. avert.org/professionals/history-hiv-aids/overview. Accessed 27 February 2019.

\section{Peer Reviewed}

Competing Interests: None declared.

Received: 23 Jun 2018; Accepted: 12 Feb 2019

Cite this article as: Sabiiti W. United Kingdom-East and Southern Africa Partnership at the Forefront of Developing the First Ever Test That Measures Patient Tuberculosis Burden in Hours. E Afr Sci. 2019;1(1):\#\#-\#\#. https://doi.org/10.24248/EASci-D-18-00008.

(C) Sabiiti. This is an open-access article distributed under the terms of the Creative Commons Attribution License, which permits unrestricted use, distribution, and reproduction in any medium, provided the original author and source are properly cited. To view a copy of the license, visit http://creativecommons.org/licenses/by/4.0/. When linking to this article, please use the following permanent link: http://doi org/10.24248/EASci-D-18-00008. 